\title{
O impacto da estratégia de crédito na liquidez e rentabilidade: uma análise das lojas de departamentos do setor de comércio varejista
}

The impact of the strategy of credit in the liquidity and yield: an analysis of the department stores of the sector of retailing

\section{Fernanda Tavares Rezende Lobato}

Mestranda em Administração na Universidade Federal de Uberlândia Endereço: Avenida Engenheiro Diniz, 1095 - Bairro Martins

CEP: 38.400-462 - Uberlândia/MG - Brasil

E-mail: fernandatavarezende@yahoo.com.br

Telefone: (34) 3214-3402

\section{Ana Paula Silva}

Mestranda em Administração na Universidade Federal de Uberlândia Endereço: Rua Pedro Urias da Silva, 198 - Bairro Luizote de Freitas CEP: 38.414-380 - Uberlândia/MG - Brasil

E-mail: anapaullas@gmail.com

Telefone: (34) 3214-3402

\section{Kárem Cristina de Sousa Ribeiro}

Pós-Doutora em Administração na Universidade de São Paulo

Professora de Finanças da Universidade Federal de Uberlândia

Endereço: Av. João Naves de Ávila, 2121 - Bloco 1F - Sala 216 - Campus Santa Mônica - Bairro Santa Mônica CEP: 38.400-902 - Uberlândia/MG - Brasil

E-mail: kribeiro@ufu.br

Telefone: (34) 3239-4132

Artigo recebido em abril de 2009. Passou por uma avaliação double blind review em novembro de 2009. Aceito em dezembro de 2009 pela Editora Científica Sandra Rolim Ensslin. 


\title{
Resumo
}

A presente pesquisa tem por objetivo demonstrar o impacto da política de crédito nos indicadores de liquidez e rentabilidade das lojas Globex Utilidades S.A., das Lojas Americanas S.A. e da Cia. Brasileira de Distribuição. Verificou-se que, para as três empresas analisadas, as políticas crédito e condições de vendas adotadas influenciam diretamente a liquidez e a rentabilidade. Estratégias de concessão de crédito mais flexíveis, quase sempre resultaram em menor liquidez e menor rentabilidade. Na maior parte do período analisado não se evidenciou trade-off entre liquidez e rentabilidade, indicando que políticas de crédito mais liberais não têm se traduzido em ganho real para as empresas, comprometendo a maximização do valor para os acionistas.

Palavras-chave: Política de Crédito, Liquidez, Rentabilidade.

\begin{abstract}
The present research has for objective to demonstrate to the impact of the credit policy in the liquidity indicators and yield of the department stores of Globex Utilidades S.A., of the Lojas Americanas S.A. and of the Cia. Brasileira de Distribuição. It was found that, for the three companies examined, the credit policies and conditions of sales taken directly influence liquidity and profitability. Strategies lending more flexible, almost always resulted in lower liquidity and lower profitability. Most of the analysis showed no trade-off between liquidity and profitability, it indicating that credit policies are more liberal have been not translated into real gains for firms, undermining the maximizing shareholder value.
\end{abstract}

Key words: Credit Policy, Liquidity, Profitability.

\section{Introdução}

A concessão de crédito representa um dos principais fatores responsáveis pelo crescimento do consumo e do padrão de vida dos cidadãos, pois ela está associada ao aumento do poder de compra do individuo e conseqüente aumento das vendas nas empresas.

Esse crédito configura-se em investimento da empresa em determinado cliente e como tal, oferece riscos e retornos que devem ser mensurados. De acordo com Brealey e Myers (1995) em certas empresas, cerca de um terço do ativo circulante está na forma de contas a receber, portanto verifica-se a necessidade da empresa estar em constante aperfeiçoamento com as suas políticas de créditos, a fim de atender o objetivo principal da administração financeira que é maximizar a riqueza dos proprietários e acionistas.

A política de crédito das empresas influencia diretamente na sua liquidez e rentabilidade. Uma política mais afrouxada, com um período médio de recebimento (PMR) mais prolongado, tende a diminuir a liquidez e aumentar a rentabilidade do empreendimento, já uma política mais enrijecida, com um PMR mais curto, tende a aumentar a liquidez e conseqüentemente, diminuir a rentabilidade. Assim, verifica-se a existência de um trade-off entre a política de crédito, liquidez e rentabilidade.

Assim ontou-se nor analisar a influência da nolítica de crédito na liaui- 
dez e rentabilidade nas lojas de departamento do setor do comércio varejista no período de 2001 a 2008, pois de acordo com o Instituto Brasileiro de Geografia e Estatística (IBGE), neste setor, observa-se um constante crescimento em suas receitas de vendas, o varejo nacional obteve, em termos de volume de vendas, acréscimos da ordem de $1,8 \%$ sobre março do ano anterior e de 3,8\% e 7,2\% nos acumulados do primeiro trimestre e dos últimos 12 meses, respectivamente.

A partir da análise de dados disponibilizados pelo IBGE e pelo BNDES, verifica-se que a disponibilidade de crédito ao consumidor é de suma importância para as vendas no comércio varejista, assim, grande maioria das empresas nesse setor oferece algum tipo de financiamento aos seus clientes, sendo importante analisar as políticas de créditos adotadas.

O problema de pesquisa que motivou essa pesquisa pode ser assim enunciado: Qual é o impacto da estratégia de concessão de crédito na liquidez e na rentabilidade das lojas de departamentos do comércio varejista?

Assim, o objetivo principal desse trabalho é analisar o impacto da estratégia de concessão de crédito na liquidez e na rentabilidade das lojas de departamento do comércio varejista. Como objetivo específico pretende-se analisar a existência do trade-off entre liquidez e rentabilidade na política de crédito das empresas Globex Utilidades S.A., das Lojas Americanas S.A. e da Cia. Brasileira de Distribuição, no período de 2001 a 2008, as quais compõem o sub-segmento das lojas de departamentos do comércio varejista.

O presente trabalho justifica-se pela relevância da política de crédito no setor varejista, pois o crédito estimula as vendas e lucratividade das empresas nesse setor.

Além desta introdução, o trabalho está divido em mais cinco seções: a segunda apresenta uma contextualização do comércio varejista brasileiro, a terceira traz uma breve revisão do referencial teórico, a quarta trata da metodologia utilizada, a quinta seção descreve a análise dos resultados e a última apresenta as conclusões.

\section{Referencial Teórico}

Os dois eixos teóricos que informam o presente estudo são explorados, em termos de revisão de literatura, nas subseções a seguir.

\subsection{Comércio Varejista}

O comércio varejista organiza-se para vender mercadorias direto ao consumidor final, representando assim, o último elo da cadeia de distribuição. As atividades desse setor classificam-se de acordo com a gama de produtos vendidos, 
a saber: combustíveis e lubrificantes, hiper, supermercados, produtos alimentícios, bebidas e fumo, tecido, vestuário e calçados, móveis e eletrodomésticos, artigos farmacêuticos, médicos, ortopédicos e de perfumaria, equipamentos e materiais para escritório, informática e comunicação, livros, jornais, revistas e papelaria, veículos e motos, partes e peças e material de construção.

Tradicionalmente, o comércio varejista é dividido em dois grandes segmentos, alimentos e não alimentos, ou, entre bens de consumo duráveis, semiduráveis e não duráveis.

Segundo o Instituto Brasileiro de Geografia e Estatística (IBGE), o comércio varejista do país, registrou alta no terceiro mês do ano de 2009, assinalando taxas de $0,3 \%$ no volume de vendas e de $0,5 \%$ na receita nominal, ambas as variações com relação ao mês anterior (ajustadas sazonalmente).

Tabela 1: Brasil - Volume de vendas do comércio varejista e comércio varejista ampliado segundo Grupos de Atividades da Pesquisa Média do Comércio - 2009

\begin{tabular}{|c|c|c|c|c|c|c|c|c|}
\hline \multirow{4}{*}{ Comércio Varejista } & \multirow{2}{*}{\multicolumn{3}{|c|}{\begin{tabular}{|c|} 
Indicadores mês/mês \\
Taxa de Variação
\end{tabular}}} & \multirow{2}{*}{\multicolumn{3}{|c|}{$\begin{array}{l}\text { Indicador Mensal } \\
\text { Taxa de Variação }\end{array}$}} & \multirow{2}{*}{\multicolumn{2}{|c|}{$\begin{array}{c}\text { Acumulado } \\
\text { Taxa de Variação }\end{array}$}} \\
\hline & & & & & & & & \\
\hline & JAN & FEV & MAR & JAN & FEV & MAR & NO ANO & 12 MESES \\
\hline & 1,9 & 1,5 & 0,3 & 6 & 3,8 & 1,8 & 3,8 & 7,2 \\
\hline 1 - Combustíveis e lubrificantes & $-1,4$ & 3 & 0,9 & 3,8 & 0,8 & 4,2 & 3 & 8,7 \\
\hline $\begin{array}{l}2 \text { - Hiper, supermercados, prods. } \\
\text { Alimentícios, bebidas e fumo }\end{array}$ & 0,7 & 2,4 & 0 & 7 & 5,7 & 0,7 & 4,3 & 4,5 \\
\hline 2.1 - Super e Hipermercados & 0,9 & 2,5 & 0 & 6,7 & 5,4 & 0,3 & 4 & 4,2 \\
\hline 3 - Tecidos, vest. E calçados & 2,3 & $-0,9$ & 1,9 & $-4,7$ & $-6,9$ & $-8,2$ & $-6,6$ & 1 \\
\hline 4 - Móveis e eletrodomésticos & 5,7 & $-1,4$ & $-2,2$ & 6,3 & $-2,1$ & $-0,9$ & 1,3 & 11,2 \\
\hline $\begin{array}{l}5 \text { - Artigos farmacêuticos, med., ortop. E } \\
\text { de perfumaria }\end{array}$ & 1,3 & 2,1 & 1,4 & 8,9 & 12 & 15,2 & 12,1 & 13,1 \\
\hline $\begin{array}{l}6 \text { - Equip. e mat. Para escritório, } \\
\text { informática e comunicação }\end{array}$ & $-11,3$ & 3,3 & 1,4 & 15,4 & 11,2 & 18 & 15 & 29,7 \\
\hline 7 - Livros, jornais, revista e papelaria & 9,2 & $-9,1$ & 1,9 & 23,9 & 1,9 & 10,5 & 12,3 & 11,4 \\
\hline $\begin{array}{l}8 \text { - Outros artigos. De uso pessoal e } \\
\text { domésticos }\end{array}$ & 6,4 & 4,5 & 1,1 & 5 & 10,5 & 5 & 6,7 & 11 \\
\hline Comércio Varejista Ampliado & 5,5 & 2,7 & 2 & 2,8 & 1,6 & 6,5 & 3,7 & 7,4 \\
\hline 9 - Veículos e motos, partes e peças & 11,7 & 4,5 & 3,9 & $-0,3$ & $-0,1$ & 17,1 & 5,9 & 8,4 \\
\hline 10 - Material de Construção & $-3,4$ & 5,2 & 3 & $-12,5$ & $-12,8$ & $-4,1$ & $-9,8$ & 3 \\
\hline
\end{tabular}

Fonte: Adaptado do IBGE, Diretoria de Pesquisas, Coordenação de Serviços e Comércio.

De acordo com os dados na Tabela 1 , verifica-se que o varejo nacional obteve, em termos de volume de vendas, acréscimos da ordem de 1,8\% sobre março do ano anterior e de 3,8\% e 7,2\% nos acumulados do primeiro trimestre e dos últimos 12 meses, respectivamente.

Segundo o Banco Nacional de Desenvolvimento Social (BNDES), o setor 
de comércio varejista caracteriza-se por possuir uma demanda com significativa sazonalidade, e ao mesmo tempo, por necessitar de um giro rápido de estoques. As políticas econômicas afetam diretamente o comércio varejista, pois seus volumes de vendas respondem rapidamente às mudanças na conjuntura macroeconômica e nos indicadores mais diretos de renda dos consumidores.

Nesse contexto, observa que disponibilidade de crédito ao consumidor é de suma importância para as vendas. Assim, nota-se que a grande maioria das empresas oferece algum tipo de financiamento aos seus clientes. Essa venda financiada é necessária para que o consumidor possa adquirir os produtos oferecidos, potencializando assim os negócios, ao passo que a empresa que oferece o crédito deve ser capitalizada em bases sólidas e possuir uma boa política de crédito, devido ao risco de inadimplências.

Figura 1: Volume de Operações de Crédito - Pessoa Física

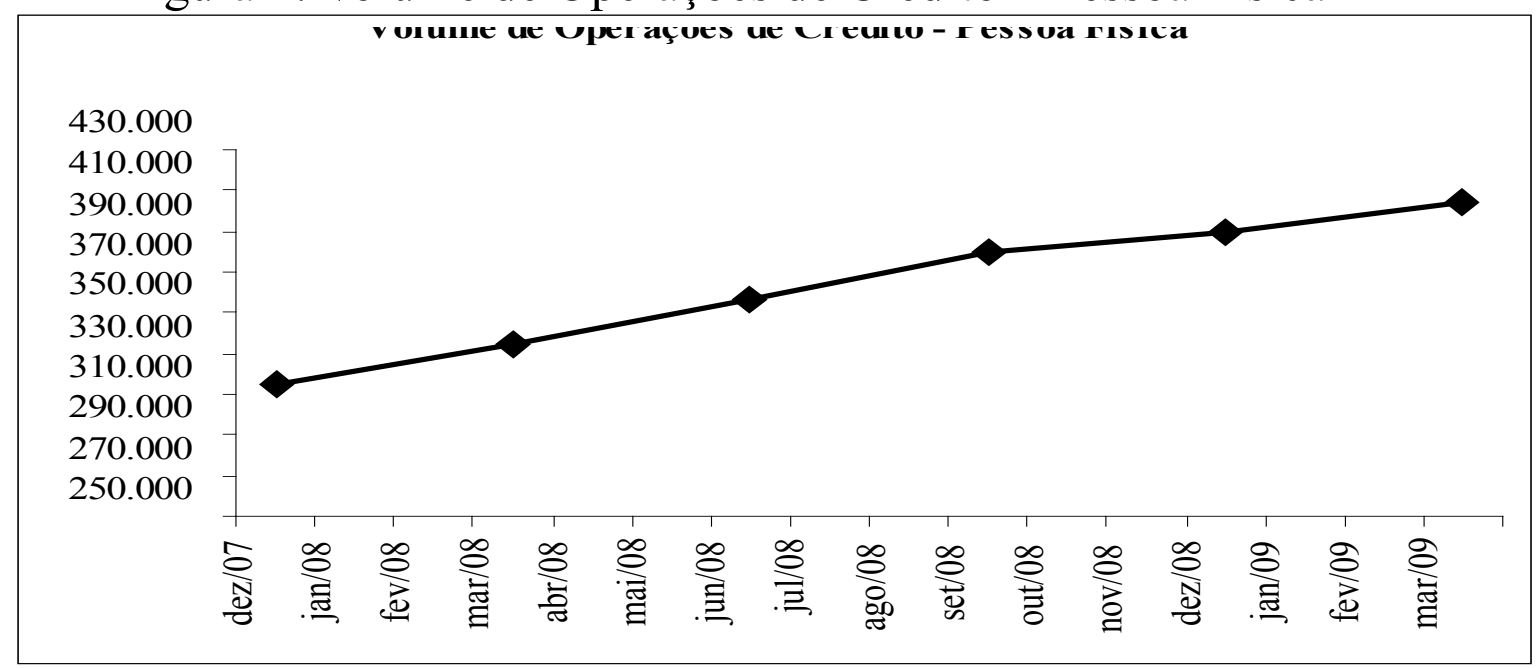

Fonte: Banco Central do Brasil (Indicadores de Conjuntura Econômica - Moeda e Crédito 2009).

A Figura 1 demonstra que o crédito pessoal está em constante crescimento nos últimos meses. Esse crédito está intimamente ligado ao consumo de curto prazo e impacta positivamente nas vendas do comércio varejista.

\subsection{Gestão de Crédito}

Nos últimos anos, a concessão de crédito tem sido um dos principais fatores responsáveis pela melhoria no padrão de vida dos consumidores e na lucratividade das empresas, pois o crédito aumenta o poder de compra dos indivíduos e das empresas (SCHERR 1989).

O mesmo autor afirma que no ciclo da gestão do capital de giro, a administração de valores a receber inicia-se quando termina a administração de estoques e termina quando a administração do caixa se inicia. No momento em que uma 
empresa vende bens e serviços, ela pode optar por receber pagamento a vista ou conceder crédito ao seu cliente, recebendo o pagamento após certo período negociado entre eles.

$\mathrm{O}$ crédito oferecido aos clientes configura-se em um importante instrumento para garantir a continuidade do empreendimento, pois ele pode refletir em um aumento das vendas e lucratividade do empreendimento. Conforme Ross, Westerfield e Jaffe (2007), ao conceder crédito, a empresa faz um investimento no cliente vinculado à venda do produto ou serviço.

A conta de balanço "créditos a receber" equivale em média a um terço do total do ativo circulante das empresas, portanto, se torna necessário a gestão dessa conta de modo a garantir sua rentabilidade (BREALEY e MYERS 1995). Sousa e Chaia (2000, p. 14) afirmam que:

Deve-se ter sempre em mente que a concessão de crédito resultante da venda a prazo representa a troca de um ativo real (um bem) por um direito a realizar-se no futuro (crédito). Assim, a política de crédito deverá ser analisada da mesma forma que qualquer outro ativo financeiro que tem risco e retorno associado.

O volume de vendas a prazo e o prazo médio de recebimento influenciam diretamente no investimento no contas a receber de uma empresa, portanto, a política de crédito adotada pela empresa deve considerar esses fatores (ROSS, WESTERFIELD e JAFFE, 2007).

Os mesmos autores (2007, p. 639) afirmam que os principais componentes de uma política de crédito são:

1. Condição de venda: uma empresa precisa estabelecer certas condições ao vender sues bens e serviços a prazo;

2. Análise de crédito: ao conceder crédito, uma empresa procura distinguir entre clientes que pagarão suas contas e clientes que não o farão;

3. Política de cobrança: as empresas que concedem crédito devem adotar uma política de cobrança de pagamentos quanto de seu vencimento.

\subsubsection{Condição de Venda}

Para se estabelecer uma condição de venda deve-se considerar três fatores: o desconto financeiro, caso o cliente pague a dívida antes da data negociada, o período de tempo que este desconto será válido e a data do vencimento da fatura onde não existirá desconto (SCHERR, 1989).

São vários os fatores que influenciam no prazo de concessão de crédito, são eles: política adotada pela concorrência, características riscos inerentes ao mercado consumidor, natureza do produto vendido, desempenho da conjuntura 
econômica, atendimento de determinadas metas gerenciais internas da empresa, mercadologia, prazo de pagamento a fornecedores, dentre outras (ASSAF NETO, 2008).

Ao oferecer o desconto ao cliente, a empresa pode estar interessada em incrementar suas vendas, adquirir novos clientes em sua carteira, além de redução da necessidade de caixa e prazo médio de cobrança (ASSAF NETO, 2008).

Segundo Ross, Westerfield e Jaffe (2007) um dos motivos para se oferecer desconto por pagamento à vista pode ser relacionado ao desejo de acelerar os pagamentos pelos clientes, porém é importante que a empresa avalie se as receitas com o recebimento por meio de desconto superar os custos ao oferecê-lo.

\subsubsection{Análise de Crédito}

Ao conceder crédito a seus clientes, a empresa procura analisar aqueles que provavelmente pagarão as dívidas contratadas e aqueles que poderão vir a não honrar com seus compromissos assumidos. Para isso, deve-se recorre a informações para determinar a qualidade do cliente (ROSS, WESTERFIELD E JAFFE, 2007).

Os mesmos autores afirmam que normalmente, as principais informações que as empresas utilizam são: avaliação dos índices financeiros com base nas demonstrações financeiras; verificação de relatórios de créditos baseados nos antecedentes do cliente com outras empresas, como o manual da empresa Dun \& Bradstreet, que contém classificação de riscos de crédito de milhares de empresas ou informações oferecidas pelos próprios bancos em relação à qualidade do cliente; análise dos antecedentes do cliente com a própria empresa, verificando se ele já deixou de pagar alguma conta anteriormente.

Scherr (1989) oferece um modelo tradicional para analisar as informações sobre a capacidade de pagamento de um cliente, ou o risco de crédito de um solicitante, conhecido como os "cinco C's do crédito":

1. Caráter: o cliente deverá ter disposição e intenção de pagar as suas dívidas. Para isso, deve-ser analisar o histórico de pagamentos efetuados pelo cliente em seus compromissos financeiros;

2. Capacidade: capacidade que o solicitante tem de gerenciar as suas operações para garantir a continuidade da empresa e geração de fluxos financeiros positivos para poder honrar seus compromissos assumidos;

3. Capital: análise da situação econômico-financeira da empresa por meio de verificação dos bens e direitos que a empresa possuir para saldar suas dívidas, bem como a sua solidez patrimonial;

4. Colaterais: garantias extras que o cliente pode oferecer para viabilizar 
a liberação do crédito;

5. Condição: características individuais e condições econômicas vigentes que podem afetar qualquer uma das partes envolvidas na negociação.

Esse método tradicional possui algumas limitações que se apresentam como desvantagem para a empresa que concederá o crédito. Sousa e Chaia (2000) as descrevem como:

- As análises produzidas podem ser inconsistentes, pois o processo de síntese depender da opinião subjetiva de diferentes analistas;

- Necessidade do analista de possuir experiências anteriores para que possa obter bons resultados, pois o analista com pouca experiência que utiliza os 5C's poderá deixar de conceder crédito para bons clientes;

- Os 5C's não levam em consideração as perdas ocasionadas pela rejeição de financiamento a bons clientes, o que reduz a rentabilidade das operações a prazo. Assim, não está diretamente relacionada ao objetivo principal da empresa que é a maximização de riqueza dos acionistas.

Pensando na concessão de crédito como um investimento na conta de créditos a receber, verifica-se a importância em se considerar os custos inerentes à recusa e à pesquisa de informações sobre os clientes na análise do crédito (SOUSA e CHAIA, 2000).

Esses mesmos autores afirmam que a partir do momento em que se incluem esses custos juntamente com a possibilidade de acontecer uma aprovação, rejeição ou aprofundar na pesquisa de análise de crédito, obtém-se uma melhor relação de custo/benefício para a tomada de decisão. Para isso, utiliza-se o método da Árvore de Decisão que se fundamenta em verificar se a aprovação do crédito será lucrativa para empresa, ou se será necessário fazer mais pesquisas antes da decisão final.

Para evitar a subjetividade inerente a decisões de análise de crédito, muitas empresas utilizam o método estatístico como o Credit Score. Esse método consiste na distribuição de pontos às variáveis de decisão, por meio de técnicas estatísticas, buscando classificar os solicitantes de crédito de acordo com a sua possibilidade de pagamente da dívida (CUNHA, COSTA e RIBEIRO, 2007).

Conforme Sousa e Chaia (2000), as principais informações consideradas no Credit Score são: residência, trabalho e estado civil. Apesar de esse método utilizar ferramentas estatísticas e ser um processo científico, ainda existe a possibilidade de liberar o crédito para um mau pagador e recusar um bom pagador e cliente em potencial, isso acontece porque os sistemas de gestão de créditos, por mais sofisticados que sejam, são conseguem fazer um levantamento de todas as 
informações relevantes para a classificação do devedor.

\subsubsection{Política de Cobrança}

Depois de efetuadas as devidas análises para a liberação de crédito, o próximo passo da empresa é monitor o desempenho do cliente, verificando se os pagamentos estão ocorrendo conforme acordado, ou se estão ocorrendo atrasos e inadimplências.

Figura 2: As três fases da gestão das vendas a prazo

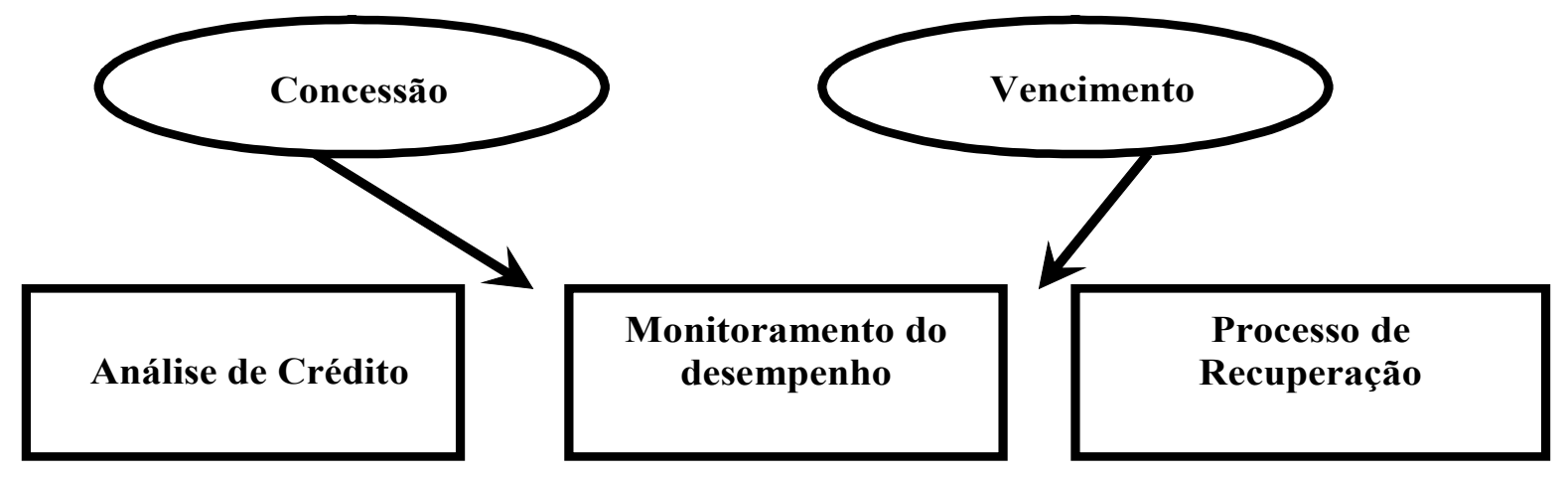

Fonte: Sousa e Chaia (2000)

Assaf Neto (2008) afirma que esse monitoramente é de grande importância e deve ser uma atividade permanente na administração financeira da empresa, levantando informações relevantes, como:

- Apurar o nível de atraso com que os clientes estão pagando;

- Identificar a pontualidade com que os clientes saldam seus compromissos;

- Entender as razões que determinam a variação na carteira de valores a receber.

Existem diversos procedimentos a serem aplicados quando existe inadimplência por parte do cliente, como, envio de cartas, telefonemas de cobrança, visita pessoal, protestos judiciais. Algumas empresas entregam o crédito a uma empresa de cobranças ou a um advogado. Esses procedimentos geram custos para a empresa, que podem girar em torno de quinze a 40 por cento do montante cobrado (BREALEY e MYERS 1995).

Scherr (1989) afirma que a maioria das empresas experimenta pouquíssimas inadimplências por devedores comerciais, mas quando um devedor é inadimplente, uma enorme quantia de dinheiro é perdida. 


\section{Metodologia da Pesquisa}

As pesquisas podem ser classificadas em três tipos, exploratórias, descritivas ou explicativas. Para Selltiz et al. (1972), a pesquisa exploratória objetiva a familiarização com um fenômeno ou uma nova compreensão deste, sua principal característica é a busca da descoberta de idéias e intuições.

A pesquisa descritiva é definida como sendo aquela em que o pesquisador apresenta o objeto de pesquisa, buscando descrever e demonstrar como determinado fenômeno ocorre, quais são suas características e relações com outros fenômenos (BARROS e LEHFELD, 2000).

Gil (2002) afirma que as pesquisas explicativas objetivam identificar os fatores que determinam ou que contribuem para a ocorrência dos fenômenos, procurando explicar a razão e o porquê das coisas.

Considerando que o objetivo deste estudo será descrever e analisar impacto da política de crédito nos indicadores de liquidez e rentabilidade das lojas de departamentos do setor de comércio varejista, o tipo de pesquisa empregado será o descritivo.

Para isso, analisou-se o prazo médio de recebimento (PMR), os índices de liquidez geral, corrente, seca e imediata, o giro do ativo, a margem líquida e a rentabilidade do ativo e do patrimônio líquido da Globex Utilidades S.A., das Lojas Americanas S.A. e da Cia. Brasileira de Distribuição, no período de 2001 a 2008.

A presente análise tomou por base dados coletados no banco de dados Economática referentes ao sub-seguimento lojas de departamentos do setor comércio varejista.

A escolha do período estudado (2001 a 2008) justifica-se pelo fato de que, a partir de 2001 os níveis de governança corporativa foram instituídos pela BOVESPA. Como as três empresas analisadas possuem ações negociadas na bolsa de valores, espera-se que elas possuam dentre outras características, uma política de crédito consistente, demonstrando assim, que elas estão atendendo as expectativas dos acionistas.

\section{Análise dos Resultados}

A presente análise tomou por base dados coletados no banco de dados Economática referentes ao subsetor lojas de departamentos do setor comércio varejista. As informações coletadas reportam-se ao período de 2001 a 2008, e correspondem aos seguintes indicadores econômico-financeiros: prazo médio de recebimento, índices de liquidez e índices de rentabilidade. As empresas que 
compuseram a amostra, e se constituem, portanto, em objeto desta análise são: Globex Utilidades S.A., Lojas Americanas S.A., e Cia. Brasileira de Distribuição - Pão de Açúcar.

A seguir são apresentados os valores dos prazos médios de recebimento no período de 2001 a 2008 para as três empresas que compõe a amostra do subsetor lojas de departamentos.

Tabela 2: Prazo Médio de Recebimento das lojas de departamentos no período de 2001 a 2008

\begin{tabular}{|c|c|c|c|}
\hline \multicolumn{3}{|c|}{ Prazo Médio de Recebimento } \\
\hline Ano & Globex Utilidades S.A. & Lojas Americanas S.A. & $\begin{array}{c}\text { Cia. Brasileira de } \\
\text { Distribuição } \\
\text { (Pão de Açúcar) }\end{array}$ \\
\hline 2001 & 62 & 38 & 30 \\
\hline 2002 & 54 & 22 & 33 \\
\hline 2003 & 61 & 28 & 20 \\
\hline 2004 & 83 & 57 & 14 \\
\hline 2005 & 88 & 82 & 31 \\
\hline 2006 & 86 & 112 & 42 \\
\hline 2007 & 94 & 74 & 44 \\
\hline 2008 & 100 & 46 & 37 \\
\hline
\end{tabular}

Fonte: Elaborada pelos autores com base nos dados coletados no Economática.

Considerando que o prazo médio de recebimento (PMR) integra a estratégia de concessão de crédito de uma empresa, observa-se que no período analisado a tendência da Globex Utilidades S.A. consiste em adotar critérios cada vez mais flexíveis para concessão de crédito.

À exceção do ano de 2002, em que houve diminuição significativa de 8 dias no PMR em relação a 2001, o PMR desta empresa apresentou comportamento crescente. A redução do PMR em 2 dias ocorrida entre os exercícios de 2005 e 2006, pode ser considerada irrelevante quando se leva em conta a evolução do PMR da empresa ao longo do período analisado.

Quanto às Lojas Americanas S.A. torna-se difícil definir um padrão para as políticas de crédito, uma vez que o PMR da empresa variou bastante no período estudado. Inicialmente, entre 2001 e 2002, há redução do PMR em 16 dias apontando para a existência de critérios de concessão de crédito mais rigorosos. Entre 2003 e 2006, as condições de venda implementadas pela empresa seguiram uma tendência de afrouxamento, indicando flexibilização na concessão de crédito. A partir de 2007, a empresa retoma a estratégia adotada em 2002 por meio de políticas de crédito mais rígidas. Desta forma, em 2007 a redução do PMR em relação a 2006 foi de 38 dias, e entre 2008 e 2007 a diminuição foi de 28 dias.

As condições de venda adotadas pela Cia. Brasileira de Distribuição 
também variam ao longo do período analisado, contudo, esta variação foi menos significativa do que aquela observada nas Lojas Americanas S.A. Em 2002 a empresa afrouxou um pouco sua política de crédito, ampliando o PMR em 3 dias. No exercício de 2003, os critérios para concessão de crédito adotados pela organização tornaram-se mais restritivos, o que pode ser evidenciado pelo PMR igual 20 dias, correspondente a uma redução de 13 dias em relação a 2002. Em 2004, a empresa parece ter optado por manter estratégias mais rígidas de crédito, o que pode estar relacionado à necessidade de maior capital de giro, resultando na diminuição do PMR em 6 dias. Entre 2005 e 2007 a estratégia de vendas e cessão de crédito implementada pela empresa foi mais flexível, levando a um aumento do PMR neste período. No ano de 2008, a empresa retoma políticas mais severas, implicando na diminuição do PMR em 7 dias.

Figura 3: Prazo Médio de Recebimento das lojas de departamentos no período de 2001 a 2008

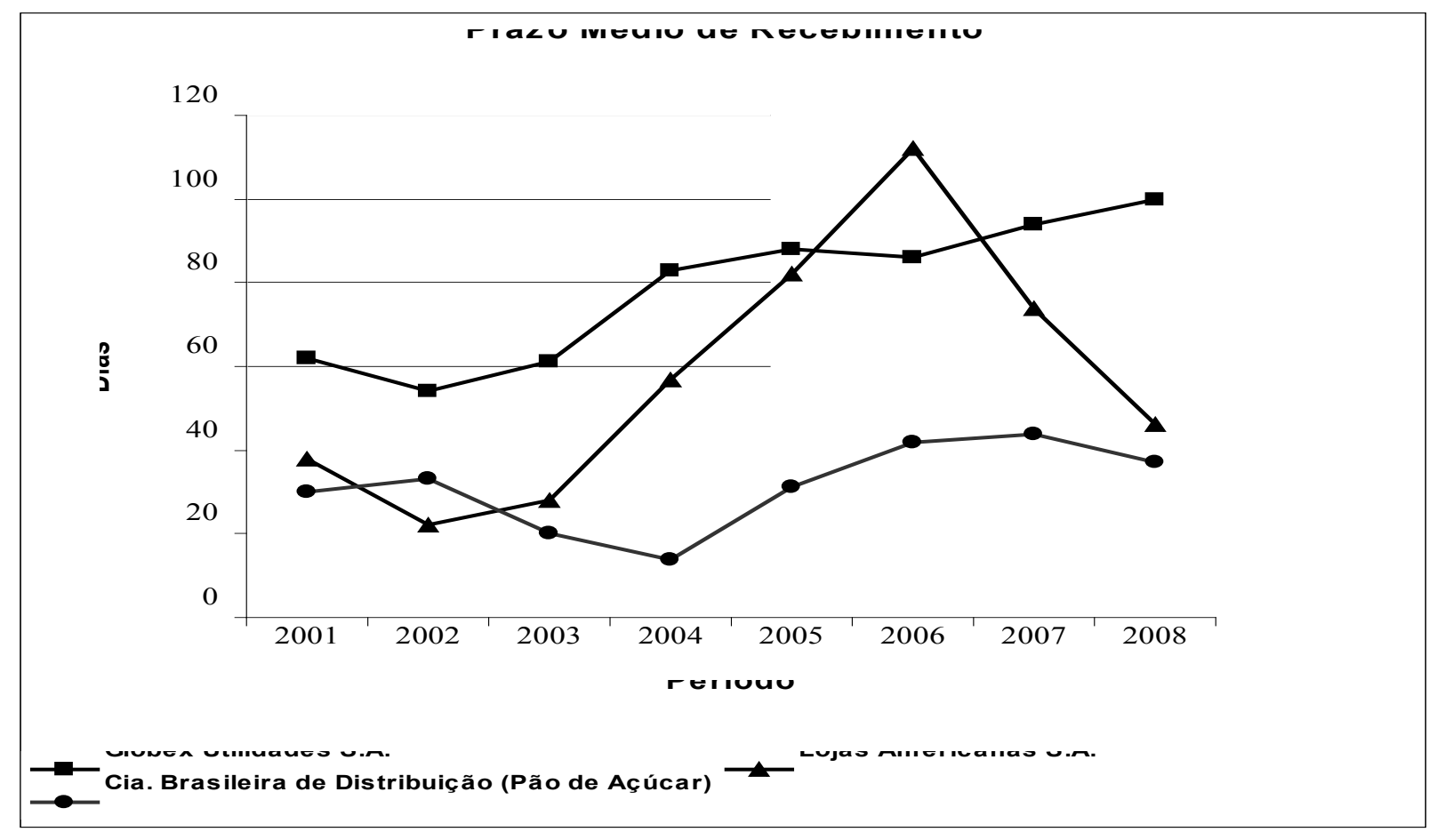

Fonte: Elaborada pelos autores com base nos dados coletados no Economática.

Observando a Figura 3, nota-se que as políticas de concessão de crédito adotadas pela Globex Utilidades S.A. e pela Cia. Brasileira de Distribuição foram quase sempre (2002, 2003, 2004, 2006 e 2008) inversas no período estudado. Assim, enquanto uma optava por flexibilizar as condições de venda, a outra adotava estratégias de maior restrição.

A estratégia de variabilidade das políticas de crédito adotada, sobretudo, pelas Lojas Americanas S.A. e pela Cia. Brasileira de Distribuição pode refletir a maior necessidade de capital de giro destas empresas nos momentos em que as 
condições de venda foram mais severas. Por outro lado, a estratégia de ampliação do crédito adotada pela Globex Utilidades S.A. possivelmente está relacionada à maior expectativa de receita de vendas.

A seguir são apresentados os índices de liquidez das três empresas analisadas, com vistas a relacioná-los com as estratégias de crédito adotadas pelas empresas, evidenciadas por meio do PMR.

Tabela 3: Índices de liquidez das lojas de departamentos no período de 2001 a 2008

\begin{tabular}{|c|c|c|c|c|}
\hline Índice & Ano & $\begin{array}{c}\text { Globex } \\
\text { Utilidades S.A. }\end{array}$ & $\begin{array}{c}\text { Lojas } \\
\text { Americanas S.A. }\end{array}$ & $\begin{array}{c}\text { Cia. Brasileira de } \\
\text { Distribuição (Pão } \\
\text { de Açúcar) }\end{array}$ \\
\hline \multirow{8}{*}{$\begin{array}{l}\text { Liquidez } \\
\text { Geral }\end{array}$} & 2001 & 1,50 & 1,10 & 0,90 \\
\hline & 2002 & 1,40 & 1,00 & 0,80 \\
\hline & 2003 & 1,40 & 1,00 & 0,80 \\
\hline & 2004 & 1,40 & 1,00 & 0,80 \\
\hline & 2005 & 1,40 & 0,90 & 0,90 \\
\hline & 2006 & 1,30 & 0,90 & 1,00 \\
\hline & 2007 & 1,30 & 0,80 & 0,90 \\
\hline & 2008 & 1,30 & 0,80 & 1,00 \\
\hline \multirow{8}{*}{$\begin{array}{l}\text { Liquidez } \\
\text { Corrente }\end{array}$} & 2001 & 2,40 & 1,60 & 1,20 \\
\hline & 2002 & 1,90 & 1,90 & 1,20 \\
\hline & 2003 & 1,50 & 1,00 & 1,10 \\
\hline & 2004 & 1,50 & 1,30 & 1,10 \\
\hline & 2005 & 1,40 & 1,40 & 1,90 \\
\hline & 2006 & 1,30 & 1,30 & 1,30 \\
\hline & 2007 & 1,30 & 1,10 & 1,20 \\
\hline & 2008 & 1,30 & 1,20 & 1,70 \\
\hline \multirow{8}{*}{$\begin{array}{l}\text { Liquidez } \\
\text { Seca }\end{array}$} & 2001 & 1,90 & 1,30 & 0,90 \\
\hline & 2002 & 1,40 & 1,60 & 0,90 \\
\hline & 2003 & 1,20 & 0,80 & 0,80 \\
\hline & 2004 & 1,10 & 1,00 & 0,70 \\
\hline & 2005 & 1,00 & 1,00 & 1,50 \\
\hline & 2006 & 1,00 & 1,00 & 1,00 \\
\hline & 2007 & 1,10 & 0,80 & 0,80 \\
\hline & 2008 & 1,00 & 1,00 & 1,20 \\
\hline \multirow{8}{*}{$\begin{array}{l}\text { Liquidez } \\
\text { Imediata }\end{array}$} & 2001 & 0,91 & 0,99 & 0,44 \\
\hline & 2002 & 0,55 & 1,33 & 0,35 \\
\hline & 2003 & 0,71 & 0,59 & 0,34 \\
\hline & 2004 & 0,29 & 0,54 & 0,34 \\
\hline & 2005 & 0,30 & 0,52 & 0,67 \\
\hline & 2006 & 0,40 & 0,47 & 0,34 \\
\hline & 2007 & 0,38 & 0,36 & 0,24 \\
\hline & 2008 & 0,07 & 0,58 & 0,48 \\
\hline
\end{tabular}

Fonte: Elaborada pelos autores com base nos dados coletados no Economática.

De modo geral, os índices de liquidez da Globex Utilidades S.A. relevaram consonância em relação à política de crédito adotada pela empresa. Os índices 
de liquidez geral, corrente e seca da empresa mostraram comportamento decrescente, o que era de se esperar, uma vez que a estratégia da empresa consiste em adotar critérios cada vez mais flexíveis para concessão de crédito. Desta forma, o aumento do PMR apresentado pela empresa, resulta em menor disponibilidade de recursos para a empresa, o que implica em menor liquidez. Contudo, ao adotar estas condições de crédito, a empresa espera que as aplicações em contas a receber sejam suficientemente rentáveis se comparadas às outras possibilidades de investimento disponíveis.

Em 2007, o índice de liquidez seca da Globex Utilidades S.A. apresentou comportamento atípico ao que vinha ocorrendo e aumento em 0,10 . Isto pode ter decorrido da gestão mais eficiente dos estoques neste período. Entre 2001 e 2002, todos os índices de liquidez da empresa apresentaram redução, contrariando o que se esperava com a redução do PMR. Uma possível razão para isso decorre do fato de que a empresa pode ter aplicado as disponibilidades resultantes de condições mais restritivas de crédito, em aplicações mais rentáveis que contas a receber.

As variações observadas no índice de liquidez imediata indicam que as políticas de concessão de crédito da Globex Utilidades S.A. poderiam ser ainda mais flexíveis, caso o investimento das disponibilidades em contas a receber seja atrativo e rentável, haja vista outras aplicações possíveis. Em outras palavras, as condições mais liberais de crédito que a empresa vem adotando encontram respaldo neste índice de liquidez, que demonstra que apesar do aumento no PMR, a organização possui disponibilidades para arcar com eventos inesperados, reduzindo o risco de não arcar com os compromissos de curto prazo.

Cabe notar que as observações acima podem não ser válidas para o ano de 2008, no qual o índice de liquidez imediata da empresa sofreu significativa redução. Contudo, o baixo nível deste índice está coerente com a política de crédito liberal adotada pela empresa, representada por um PMR igual a 100 dias, significando que as disponibilidades estão em boa parte aplicadas em contas a receber.

No caso das Lojas Americanas S.A, nota-se que apesar das políticas de crédito restritivas implementadas em alguns períodos (2002, 2007 e 2008), o comportamento de decréscimo do índice de liquidez geral indica que nestes períodos a empresa aplicou os recursos disponíveis em outros investimentos mais rentáveis que contas a receber. Nos períodos em que houve flexibilização das condições de venda e crédito, o comportamento do índice de liquidez geral mostrou-se coerente com o maior PMR adotado.

O comportamento do índice de liquidez corrente das Lojas Americanas S.A. apresentou-se em conformidade com as estratégias de crédito adotadas pela empresa, aumentando o PMR, este índice diminui. Entretanto, três períodos apresentaram índices de liquidez corrente contrastantes com aqueles esperados, considerando as variações ocorridas no PMR, a saber: 20042005 e 2007. 
As variações no índice de liquidez seca das Lojas Americanas S.A. também se mostraram coerentes com as políticas de crédito adotadas pela empresa nos seguintes anos: 2001, 2002, 2003 e 2008. Entre 2004 e 2006, este índice manteve-se constante, contrariando a expectativa de queda decorrente do aumento do PMR, o que pode ser justificado pela gestão eficiente de estoques. Em 2007, as condições de venda da empresa tornam-se mais severas, esperando-se com isso, aumento na liquidez, contudo, o índice de liquide seca diminui 0,20 , o que pode denotar perda de eficiência no gerenciamento de estoques.

Analisando-se os indicadores de liquidez imediata das Lojas Americanas S.A., percebe-se que o índice guardou coerência com as estratégias de vendas e crédito implementadas pela empresa no período estudado. $\mathrm{O}$ ano de 2007 foi o único que apresentou comportamento inverso: a diminuição do PMR foi acompanhada pela queda deste índice. Um possível razão para este comportamento refere-se à opção da empresa em diminuir os investimentos em contas a receber e direcioná-lo a outras aplicações mais rentáveis.

A partir da análise dos índices de liquidez da Cia. Brasileira de Distribuição, verifica-se que nos anos de 2003, 2004 e 2005 o impacto esperado pelas políticas de crédito (PMR) na liquidez da empresa não se evidenciou. Cabe aqui a mesma abordagem dada aos índices de liquidez imediata das Lojas Americanas S.A.: um motivo provável para o comportamento inverso ao esperado dos índices de liquidez da Cia. Brasileira de Distribuição pode estar relacionado à decisão da empresa em reduzir aplicações em recebíveis em detrimento de outras mais rentáveis.

Figura 4: Liquidez corrente das lojas de departamentos no período de 2001 a 2008

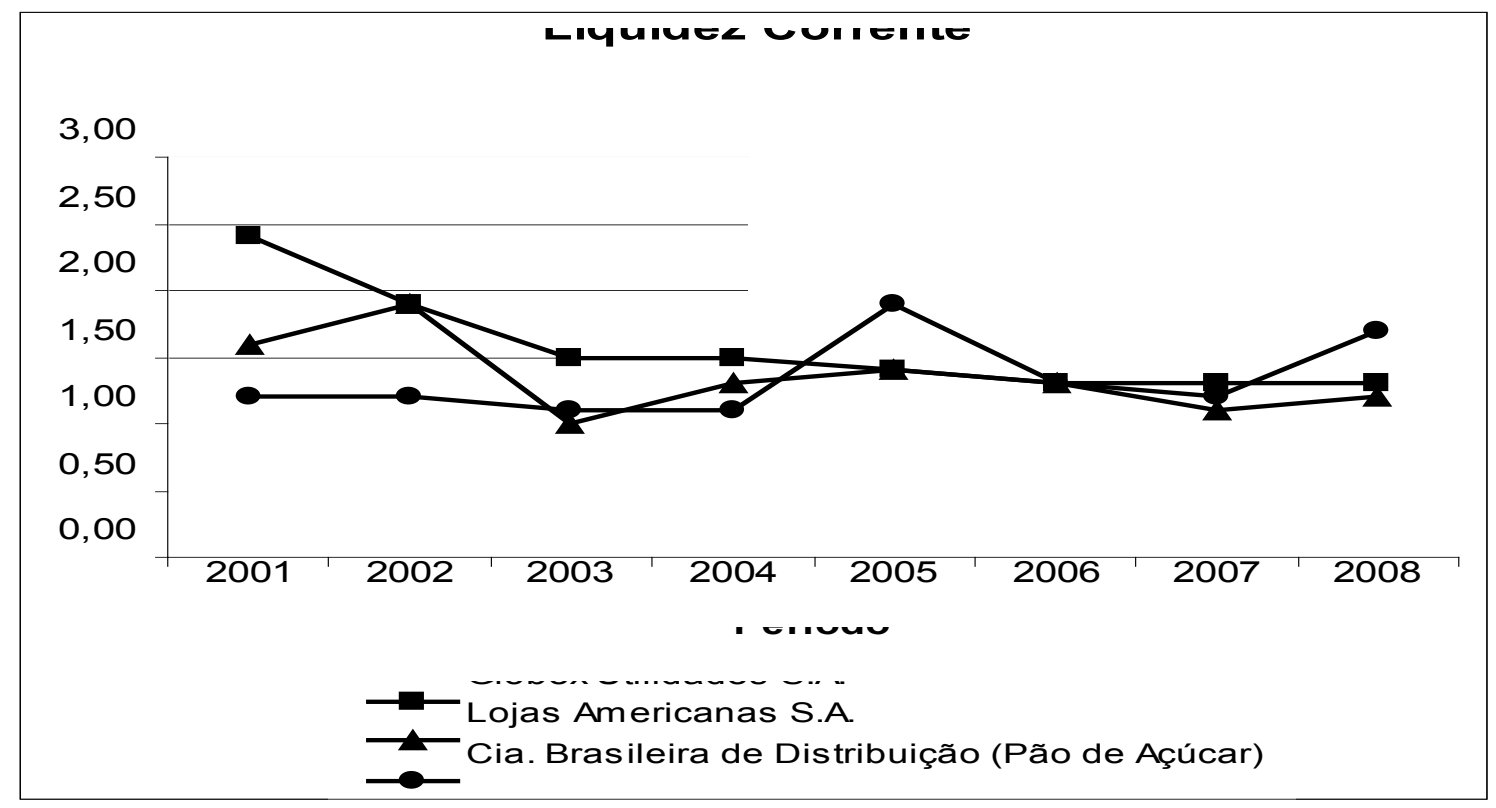

Fonte: Elaborada pelos autores com base nos dados coletados no Economática.

A partir da Figura 4 verifica-se que o comportamento do índice de liquidez 
corrente das empresas analisadas é bastante variado. Comparando-se esta figura com a Figura 3, evidencia-se que os índices de liquidez corrente da Globex Utilidades S.A. são os que guardam maior coerência com os efeitos esperados das políticas de crédito, expressas por meio do PMR.

A Tabela 4 traz os índices de rentabilidade das empresas analisadas. Estes dados serão analisados com o intuito de verificar sua relação com o PMR e com os índices de liquidez.

Tabela 4: Índices de rentabilidade das lojas de departamentos no período de 2001 a 2008

\begin{tabular}{|c|c|c|c|c|}
\hline Índice & Ano & $\begin{array}{c}\text { Globex } \\
\text { Utilidades S.A. }\end{array}$ & $\begin{array}{c}\text { Lojas } \\
\text { Americanas S.A. }\end{array}$ & $\begin{array}{l}\text { Cia. Brasileira de } \\
\text { Distribuiç̧ão (Pão } \\
\text { de Açúcar) }\end{array}$ \\
\hline \multirow{8}{*}{ Giro do Ativo } & 2001 & 1,8 & 1 & 1,1 \\
\hline & 2002 & 1,6 & 1,1 & 1 \\
\hline & 2003 & 1,4 & 1,1 & 1,2 \\
\hline & 2004 & 1,5 & 1,1 & 1,2 \\
\hline & 2005 & 1,6 & 1 & 1,2 \\
\hline & 2006 & 1,4 & 0,9 & 1,2 \\
\hline & 2007 & 1,2 & 1,1 & 1,2 \\
\hline & 2008 & 1,6 & 1,1 & 1,3 \\
\hline \multirow{8}{*}{$\begin{array}{l}\text { Margem } \\
\text { Líquida }\end{array}$} & 2001 & 1,7 & 4 & 3,1 \\
\hline & 2002 & 1,5 & 6,5 & 2,6 \\
\hline & 2003 & 0,2 & 6 & 2,1 \\
\hline & 2004 & 2 & 2,8 & 2,9 \\
\hline & 2005 & 1,9 & 6,4 & 1,9 \\
\hline & 2006 & 2,5 & 3,3 & 0,6 \\
\hline & 2007 & 2,6 & 1,8 & 1,4 \\
\hline & 2008 & 0,4 & 1,7 & 1,4 \\
\hline \multirow{8}{*}{$\begin{array}{l}\text { Rentabilidade } \\
\text { do Ativo }\end{array}$} & 2001 & 3 & 4,1 & 3,4 \\
\hline & 2002 & 2,4 & 6,9 & 2,7 \\
\hline & 2003 & 0,2 & 6,3 & 2,5 \\
\hline & 2004 & 3 & 3,1 & 3,5 \\
\hline & 2005 & 3,1 & 6,4 & 2,4 \\
\hline & 2006 & 3,4 & 2,9 & 0,7 \\
\hline & 2007 & 3,2 & 2 & 1,7 \\
\hline & 2008 & 0,7 & 1,8 & 1,9 \\
\hline \multirow{8}{*}{$\begin{array}{c}\text { Rentabilidade } \\
\text { do Patrimônio } \\
\text { Líquido }\end{array}$} & 2001 & 7,1 & 25,9 & 7,4 \\
\hline & 2002 & 6,4 & 47,2 & 6,8 \\
\hline & 2003 & 0,6 & 54,9 & 6 \\
\hline & 2004 & 8,7 & 34 & 9,1 \\
\hline & 2005 & 8,8 & 59,6 & 6 \\
\hline & 2006 & 11,7 & 37,3 & 1,8 \\
\hline & 2007 & 12,3 & 35,6 & 4,2 \\
\hline & 2008 & 2,2 & 36,3 & 4,8 \\
\hline
\end{tabular}

Fonte: Elaborada pelos autores com base nos dados coletados no Economática.

Analisando os indicadores de rentabilidade da Globex Utilidades S.A. 
nota-se que a empresa diminui o giro de seus ativos, reduziu a margem líquida, a rentabilidade do ativo e rentabilidade do patrimônio líquido entre 2001 e 2003 , no período de 2004 a 2007 estes índices de rentabilidade cresceram, e em 2008 voltaram a cair.

A redução do giro dos ativos no período analisado está coerente com a política de concessão de crédito adotada pela empresa, uma vez que esta apresenta PMR crescente ao longo do período.

Quanto aos índices de rentabilidade da Globex Utilidades S.A. verificase que, nem sempre o trade-off apontado na literatura acadêmica entre liquidez e rentabilidade ocorreu. Entre 2001 e 2003, tanto os índices de liquidez quanto os de rentabilidade da empresa comportaram-se de maneira decrescente. Isso revela que apesar das políticas de crédito mais liberais adotadas pela empresa, o aumento nas vendas e na rentabilidade esperados com esta estratégia não foram alcançados no período de 2001 a 2003.

De 2004 a 2007 os índices de rentabilidade da empresa cresceram, ao passo que os indicadores de liquidez mostraram tendência à redução. Neste período, o trade-off liquidez e rentabilidade abordado na literatura foi constatado, indicando que as condições de venda mais flexíveis implementadas pela Globex Utilidades S.A. converteram-se em maior rentabilidade.

Em 2008, os índices de rentabilidade da empresa caíram significativamente, enquanto os índices de liquidez mantiveram a tendência de decréscimo verificada até então. Os baixos índices de rentabilidade verificados neste ano podem significar que o aumento nas vendas esperado com a adoção de critérios menos rigorosos para concessão de crédito (PMR igual a 100 dias em 2008) não ocorreu, ou que, por outro lado, o aumento nas vendas não foi suficiente para cobrir o incremento nos custos e as despesas com inadimplência.

As Lojas Americanas S.A. exibiram um giro do ativo praticamente constante ao longo período estudado, o que contrasta com as variações observadas no PMR da empresa. Teoricamente, quando a empresa aumenta seu PMR, verifica-se diminuição no giro do ativo. Por outro lado, apesar do comportamento praticamente constante do giro dos ativos, em 2006 este indicador apresentou seu menor valor - 0,9, ao passo que o PMR foi o maior do período analisado - 112 dias. Assim, em 2006 a relação entre o giro do ativo e o PMR identificada na literatura acadêmica, foi confirmada.

Considerando que apesar dos índices de liquidez das Lojas Americanas S.A. terem apresentado ao longo do período analisado tendência à redução, houve variação de comportamento entre os próprios índices, para análise do trade-off entre rentabilidade e liquidez, utilizar-se-á o índice de liquidez corrente.

Entre 2001 e 2003 a margem líquida, a rentabilidade do ativo e a rentabilidade do patrimônio líquido aumentaram, enquanto a liquidez corrente neste 
período diminuiu. A constatação deste trade-off pode indicar que a estratégia de condições de vendas mais severas adotadas pela empresa no período parece ser acertada. Possivelmente a empresa aproveitou as disponibilidades para investir em aplicações mais rentáveis que contas a receber.

Em 2004 os índices de rentabilidade da empresa sofrem significativa redução, ao passo que a liquidez corrente aumenta. Neste caso mesmo ampliando seus investimentos em contas a receber, com um PMR de 57 dias, a empresa deixou de ganhar por manter maiores disponibilidades ao invés de aplicá-las em investimentos mais rentáveis. Por outro lado, a baixa rentabilidade neste ano pode estar relacionada à ineficiência da política de crédito da empresa, cuja flexibilização não se refletiu em maior retorno.

No ano de 2005 os indicadores de rentabilidade acompanharam o comportamento da liquidez corrente, a qual aumentou. O PMR no ano também aumentou, retratando a estratégia em adotar condições de vendas mais liberais. Pode-se dizer que a política de crédito implementada pela empresa mostrou-se eficiente na medida em que resultou no aumento da rentabilidade. Por outro lado, as Lojas Americanas S.A. poderiam auferir maior retorno, se mantivessem um menor nível de liquidez, e direcionassem parte dos recursos disponíveis a investimentos mais rentáveis.

No período de 2006 a 2008, os índices de rentabilidade das Lojas Americanas S.A. diminuíram, bem como seu índice de liquidez corrente e o PMR. Políticas de crédito mais restritivas e redução da liquidez significam que a empresa está aplicando recursos em outros investimentos que não contas a receber, os quais julga serem mais rentáveis. Contudo, a rentabilidade esperada para estes investimentos não se confirma.

A partir da análise do giro dos ativos da Cia. Brasileira de Distribuição nota-se que este se manteve praticamente constante, relevando que a estratégia de crédito da empresa, representada pelo PMR, tem pouca influência na gestão do giro do ativo.

Durante o período analisado, os indicadores de rentabilidade Cia. Brasileira de Distribuição diminuíram e a liquidez aumentou. Isso revela que a política de crédito adotada pela empresa, que apesar variabilidade, configura-se como restritiva se comparada às outras empresas analisadas, não tem se mostrado eficiente. Assim, a opção por baixos investimentos em recebíveis não tem se traduzido em maior retorno.

Entre 2001 e 2003 a Cia. Brasileira de Distribuição apresentou queda na rentabilidade, bem como na liquidez e no PMR. Isto significa que as restrições nas condições de crédito, optando por menores investimentos em recebíveis em detrimento de outros supostamente mais rentáveis, não se traduziram em maior retorno para a empresa, ao contrário se refletiram em menor rentabilidade. 
Em 2004, a empresa experimentou aumento nos indicadores de rentabilidade, a liquidez manteve-se constante e a política de crédito foi mais severa com redução do PMR. A maior rentabilidade indica melhor gestão na escolha dos investimentos da empresa, que se mostrou hábil em escolher opções mais rentáveis que contas a receber.

Os índices de rentabilidade da Cia. Brasileira de Distribuição diminuíram entre 2005 e 2006, no mesmo período a liquidez apresentou redução e a estratégia de crédito da empresa foi mais liberal. Contudo, a mudança na política de crédito não se refletiu em maior retorno, o que pode decorrer do fato das vendas não terem atingindo as expectativas, ou não serem suficientes para cobrir o aumento nos custos e fazer face às perdas com inadimplência.

Entre 2007 e 2008, a rentabilidade da empresa aumentou levemente, a liquidez também aumentou e o PMR diminuiu um pouco, mas, pode-se considerar a estratégia de crédito adotada pela empresa no período relativamente flexível se comparada a todo o período analisado (2001 a 2008). Estes resultados relacionamse a uma melhor gestão das contas a receber. Contudo, a maior liquidez apresentada releva que há disponibilidades que podem ser melhor aplicadas a fim de ampliar a rentabilidade da empresa.

Analisando-se as variações nos índices de rentabilidade da Cia. Brasileira de Distribuição verifica-se não haver trade-off com a liquidez. Contudo, quando se avalia o comportamento destes índices considerando a evolução entre $2001 \mathrm{e}$ 2008, nota-se que este trade-off se faz presente, haja vista que comparando 2001 a 2008, a liquidez da empresa aumentou e a rentabilidade diminuiu.

Figura 5: Margem líquida das lojas de departamentos no período de 2001 a 2008

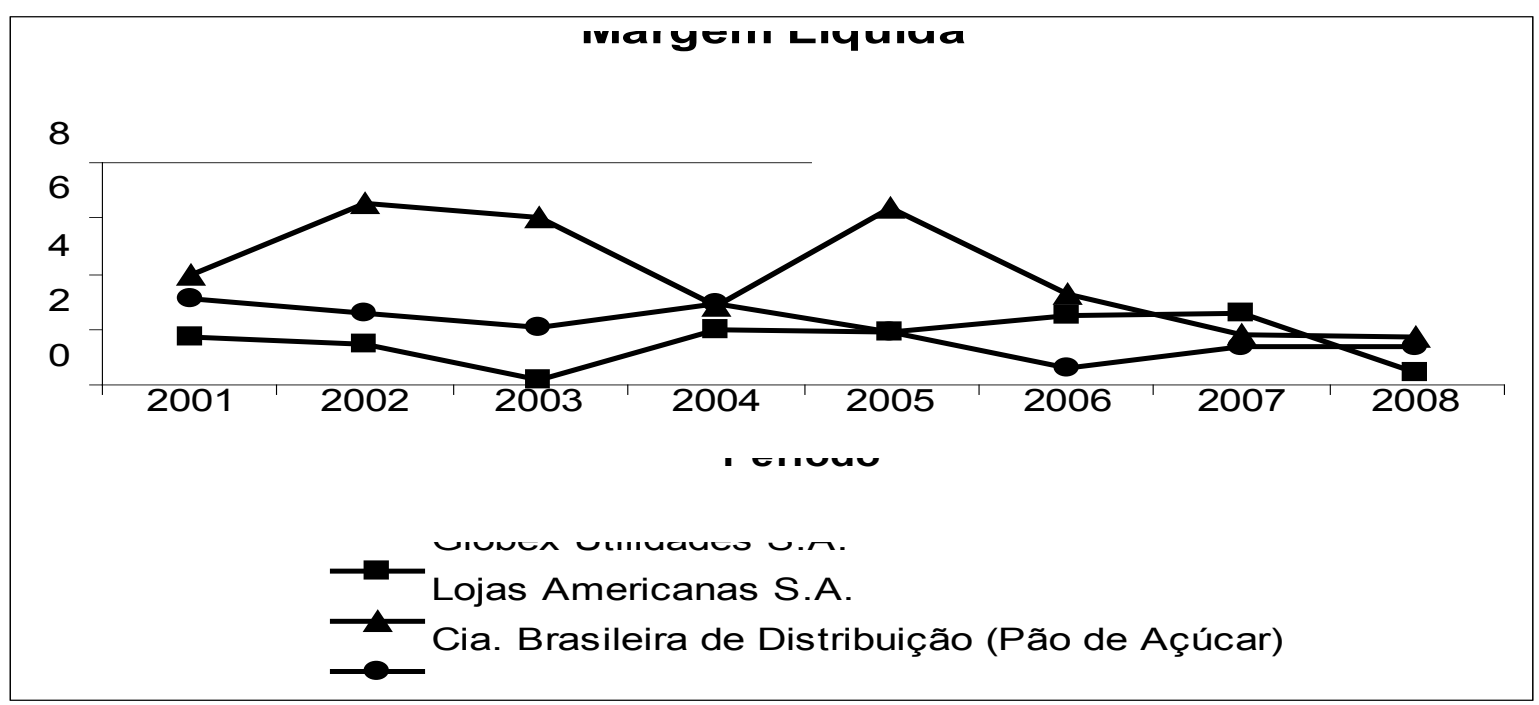

Fonte: Elaborada pelos autores com base nos dados coletados no Economática.

Optou-se por apresentar os resultados da margem líquida das empresas em um gráfico, pelo fato deste indicador estar diretamente relacionado às vendas 
líquidas, relacionando-as ao lucro líquido. Isto se justifica pelos desdobramentos que a política de crédito e as condições de venda desencadeiam nas vendas, tanto em volume quanto em valor monetário.

As análises feitas até aqui abordaram as variações e nuances do PMR, dos índices de liquidez e de rentabilidade das três empresas no período de 2001 a 2008. A seguir, faz-se uma breve avaliação destes parâmetros (PMR, índices de liquidez e de rentabilidade) considerando apenas os resultados do último período estudado - 2008 com os do primeiro período analisado - 2001 .

As três empresas estudadas mostram tendência de adotar políticas de crédito mais liberais e condições de venda mais atrativas, por meio do aumento de seu PMR. Os indicadores de liquidez e rentabilidade da Globex Utilidades S.A. e das Lojas Americanas diminuíram entre 2001 e 2008. Faz-se exceção apenas à rentabilidade do patrimônio líquido das Lojas Americanas, que exibiu aumento no referido período.

Desta forma, nota-se que para estas duas empresas não se verificou o trade-off trazido pela literatura entre liquidez e rentabilidade. Estes resultados revelam que apesar das políticas de crédito mais liberais adotadas pelas empresas, representadas pelo aumento do PMR, o aumento nas vendas e na rentabilidade esperados com esta estratégia não foram alcançados.

Embora o PMR praticado pela Cia. Brasileira de Distribuição tenha aumentado no período analisado, pode-se dizer que comparativamente às outras empresas, sua polícia de concessão de crédito é mais restritiva. Os índices de liquidez da empresa aumentaram e a rentabilidade diminuiu entre 2001 e 2008, evidenciando o trade-off entre estes indicadores proposto pela teoria. Isto indica que a política de crédito e as condições de venda adotadas pela empresa, consideradas restritivas se comparadas às outras empresas analisadas, não têm se mostrado eficientes. Assim, a opção por baixos investimentos em recebíveis não tem se traduzido em maior retorno. Por outro lado, o aumento dos níveis de liquidez indica que a gestão da empresa na escolha das aplicações mais rentáveis tem se mostrado ineficiente ineficaz.

Quanto ao giro do ativo, a Globex Utilidades S.A. apresentou redução, o está coerente com a estratégia de concessão de crédito adotada pela empresa, haja vista o PMR crescente ao longo do período. As Lojas Americanas S.A. e a Cia. Brasileira de Distribuição exibiram leve aumento no giro do ativo, contrastando com o aumento observado no PMR das empresas. Teoricamente, quando a empresa aumenta seu PMR, verifica-se diminuição no giro do ativo.

\section{Considerações Finais}

O comportamento dos índices de liquidez mostrou-se coerente com as 
políticas de crédito adotadas pelas empresas na maior parte do período estudado. Quanto maior o PMR, menor a liquidez da empresa, pois maiores recursos estão aplicados em contas a receber, diminuindo as disponibilidades.

Contudo, na maior parte do período analisado não se evidenciou o tradeoff entre liquidez e rentabilidade, pois a menor liquidez das empresas não implica necessariamente em maior rentabilidade, uma vez que embora as disponibilidades sejam menores, o que apontaria para maiores investimentos em aplicações mais rentáveis, os recursos estão aplicados em contas a receber. Importa avaliar se os investimentos empreendidos em contas a receber estão remunerando o capital ao retorno requerido.

O fato de não se verificar o esperado trade-off entre liquidez e rentabilidade, indica que o retorno oferecido pelos recebíveis não tem sido satisfatório, ou em outras palavras, que o aumento nas vendas resultante de políticas de crédito mais liberais, evidenciadas pelo aumento do PMR das três empresas no período analisado, não tem se traduzido em ganho real para as empresas, comprometendo a maximização do valor para os acionistas. Isto pode decorrer do fato das vendas não terem atingindo as expectativas, ou não serem suficientes para cobrir o incremento nos custos e fazer face às perdas com inadimplência.

Verificou-se, contudo, que para as três empresas analisadas as políticas crédito e condições de vendas adotadas influenciam diretamente a liquidez e a rentabilidade. Estratégias de concessão de crédito mais flexíveis, quase sempre resultaram em menor liquidez e menor rentabilidade. Cabe mencionar que a redução dos níveis de rentabilidade, a partir do aumento do PMR, aponta para a baixa rentabilidade dos investimentos em valores a receber ou para a má gestão deste ativo.

As perspectivas que se configuram para o segmento de lojas de departamentos do comércio varejista brasileiro, a partir dos resultados obtidos com as três empresas analisadas, traçam um cenário de crescente flexibilização das políticas de crédito e condições de venda, baixa liquidez e rentabilidade decrescente. A redução da liquidez resulta de estratégias de crédito mais liberais e, deveria, ao menos em princípio teórico, representar aumento da rentabilidade das empresas, por meio da retirada de recursos das "disponibilidades" e aplicação em recebíveis. Todavia, esta tendência não se confirmou no segmento estudado, o que indica que as empresas estudadas deveriam rever suas estratégias de concessão de crédito, pois o retorno esperado com estas estratégias não se efetivou.

Diante disso, sugere-se que as empresas analisadas reavaliem seus investimentos em contas a receber, redirecionando suas aplicações a fim de assegurar aumento de seus níveis de rentabilidade. Sob outra perspectiva, as empresas devem repensar a forma de gestão de recebíveis, pois a resposta para os baixos índices de rentabilidade pode estar na ineficácia e ineficiência da gestão de contas a receber 
e, não na implementação de políticas de crédito liberais. Este esforço de repensar a estratégia e a gestão de crédito constitui-se em tarefa fundamental, pois se mantiverem a política de expansão do crédito nos moldes de então, as empresas estudadas continuarão a experimentar indicadores de rentabilidade inexpressivos, comprometendo sua geração de valor, a maximização da riqueza para os acionistas e a sustentabilidade no competitivo mercado em que estão inseridas - lojas de departamentos do comércio varejista brasileiro.

\section{Referências}

ASSAF NETO, Alexandre. Finanças corporativas e valor. 3.ed. São Paulo: Atlas, 2008.

BANCO CENTRAL DO BRASIL (BC). Economia e Finanças - Indicadores de conjuntura - Indicadores econômicos, cap. II - Moeda e crédito: Operações de crédito do sistema financeiro - Saldo por atividade econômica. Disponível em: http://www.bcb.gov.br/?INDECO. Acesso em: 16 mai. 2009.

BANCO NACIONAL DE DESENVOLVIMENTO ECONÔMICO E SOCIAL (BNDES). Estudos e publicações. Disponível em: http://www.bndes.gov.br/ conhecimento/setorial/get4is12.pdf. Acesso em: 16 mai. 2009.

BARROS, Aidil de Jesus da Silveira; LEHFELD, Neide Aparecida de Souza. Fundamentos de metodologia científica: um guia para a iniciação científica. 2 . Ed. São Paulo: Makron Books, 2000.

BEUREN, Ilse Maria (org). Como elaborar trabalhos monográficos em contabilidade: teoria e prática. 3. ed. São Paulo, Atlas, 2006.

BREALEY, Richard A.; MYERS, Stewart C. Princípios de finanças empresarias. 3. Ed. São Paulo: McGraw Hill de Portugal Ltda., 1995.

CUNHA, Raquel L., COSTA, Brener E., RIBEIRO, Karem. C. S. Trade-Off: Políticas de Crédito X Vendas e Provisão para Contas Duvidosas. In: Simpósio de Excelência em Gestão e Tecnologia - SEGET.Anais, Resende: RJ, 2007. Disponível em: http://www.aedb.br/seget/artigos07/1295_Seget_2.pdf. Acesso em: 16 mai. 2009.

GIL, Antonio Carlos. Como elaborar projetos de pesquisa. 4. ed. São Paulo: Atlas, 2002.

INTITUTO BRASILEIRO DE GEOGRAFIA E ESTATÍSTICA (IBGE). Indi- 
cador Conjuntural - Publicação Completa. Disponível em: http://www.ibge. gov.br/home/estatistica/indicadores/comercio/pmc/default.shtm. Acesso em: 16 mai. 2009.

ROSS, Stephen A.; WESTERFIELD, Randolph W.; JAFFE, Jeffrey F. Administração financeira. 2 ed. São Paulo: Atlas, 2007.

SCHERR, F. C. Modern Working Capital Management. São Paulo: PrenticeHall, 1989.

SELLTIZ, C. et al. Métodos da pesquisa nas relações sociais. 2. ed. São Paulo: Herder, 1972.

SOUSA, A. F.; CHAIA, A. J. Política de Crédito: Uma Análise Qualitativa dos Processos em Empresas. Caderno de Pesquisas em Administração, São Paulo, v. 07, n. 3, p.13-25, jul./ set. 2000. 
